\title{
Diagnosis of Subcutaneous Metastatic Deposits by Fine Needle Aspiration
}

Bita Geramizadeh ${ }^{1,2 *}$, Saeed Marzban ${ }^{3}$, Nazanin Karamifar ${ }^{1}$, Navid Omidifar ${ }^{1}$, Mansooreh Shokripour ${ }^{1}$ and Mohammad Reza Mokhtareh ${ }^{1}$

${ }^{1}$ Department of Pathology, Transplant Research Center, Shiraz University of Medical Sciences, Shiraz, Iran

${ }^{2}$ Transplant Research Center, Transplant Research Center, Shiraz University of Medical Sciences, Shiraz, Iran

${ }^{3}$ Department of Plastic Surgery, Transplant Research Center, Shiraz University of Medical Sciences, Shiraz, Iran

\begin{abstract}
Objectives: Subcutaneous tissue is an uncommon site of metastasis. Overall it can be seen in $0.8-4 \%$ of the malignancies. Fine Needle Aspiration Cytology (FNAC) is a method for the diagnosis of subcutaneous metastasis and to exclude other differential diagnoses such as primary cutaneous tumors or inflammatory process. In this study we want to report our experience with Fine Needle Aspiration (FNA) of subcutaneous metastasis in 25 patients with known malignancy.
\end{abstract}

Study design: During 3 years, among more than 10000 cytology cases, we had 25 patients with different types of malignancy who were referred with subcutaneous nodules. FNA was performed.

Results: In these 25 patients, there were 15 males and 10 female patients (22-80 years of age). Most common malignancy was breast cancer and the most common site of metastasis was subcutaneous tissue of chest wall. FNAC was $100 \%$ accurate for the diagnosis of subcutaneous metastasis. There were no false positive and false negative cases.

Discussion and conclusion: FNAC is an accurate, noninvasive and fast method for the diagnosis of subcutaneous metastasis in the patients with a known malignancy without any complication.

Keywords: Subcutaneous metastasis; Fine needle aspiration cytology

\section{Introduction}

Subcutaneous metastatic deposits are rare and can be seen in 0.8 $4 \%$ of the patients with a known malignancy [1]. In most of the patients, subcutaneous metastasis reveals a terminal stage of the illness, so using a noninvasive method for the diagnosis or exclusion of metastasis is crucial [2]. Metastatic skin nodules may mimic primary skin tumors or inflammatory process and needs histopathologic or cytological confirmation [3].

Fine Needle Aspiration Cytology (FNAC) is an excellent noninvasive method for early diagnosis of subcutaneous nodules, which in the presence of characteristic cytomorphology obviates the need for more invasive methods and surgery [4].

In this study we tried to evaluate the role of FNAC in the diagnosis of subcutaneous metastasis in 25 patients with a known malignancy during 3 years (2009-2012).

\section{Material and Methods}

During 3 years (2009-2012), among more than 10000 cytology cases in our center, we had 25 patients with a known malignancy, presented with subcutaneous masses (nodules).

Cases with skin nodules at the site of previous surgery were excluded from the study, also cases suspected as primary tumors of skin/subcutaneous tissue were excluded from the study.

FNAC was performed using a 22-gauge needle and $10-\mathrm{ml}$ disposable plastic syringe. At least 3 passes were made in the mass while maintaining negative pressure. Aspirated material was used to prepare air-dried as well as alcohol fixed smears. At least 3 air-dried smears were stained by Wright method. At least 3 alcohol-fixed smears were also stained using Papanicoloau method.

For the diagnosis of sample adequacy we needed to have at least 2 clusters of malignant cells or at least 10 isolated cells in each case.

\section{Results}

During 3 years (2009-2012), there were 25 patients with a known malignancy who has been referred for FNA of a subcutaneous nodule. There were 10 females and 15 male patients. The age range was $15-80$ years (mean age of 55).

Table 1 shows sites of metastasis and other characteristics in cases with known primary organ malignancy.

The most common site of malignancy was breast (in 6 patients) (Figures $1 \mathrm{a}$ and $1 \mathrm{~b}$ ). We had 2 cases of transitional cell carcinoma of bladder metastatic to the neck. They were of higher grade in comparison with the primary bladder cancer. (Figure 2) Two cases of laryngeal Squamous Cell Carcinoma (SCC), one lung SCC and two other esophageal SCC had the same cytomorphology. (Figure 3) There was a liver transplant patient (with primary hepatitis B related cirrhosis) who developed subcutaneous abdominal nodule a year after transplant which was typical for Hepatocellular Carcinoma (HCC). (Figure 4) Another patient was also a known case of HCC with a subcutaneous metastasis in the abdominal wall only 4 months after the primary diagnosis and surgery of the liver mass.

There were also adrenocortical carcinoma metastatic to the elbow (Figure 5), testicular choriocarcinoma to chin, and colon carcinoma metastatic to thigh.

*Corresponding author: Bita Geramizadeh, Department of Pathology, Transplant Research Center, Shiraz University of Medical Sciences, Shiraz, Iran, PO BOX: 71345-1864, Tel: 0098-711-6474331; E-mail: geramib@sums.ac.ir

Received July 04, 2012; Accepted July 24, 2012; Published July 26, 2012

Citation: Geramizadeh B, Marzban S, Karamifar N, Omidifar N, Shokripour M, et al. (2012) Diagnosis of Subcutaneous Metastatic Deposits by Fine Needle Aspiration. J Cytol Histol 3:151. doi:10.4172/2157-7099.1000151

Copyright: () 2012 Geramizadeh B, et al. This is an open-access article distributed under the terms of the Creative Commons Attribution License, which permits unrestricted use, distribution, and reproduction in any medium, provided the original author and source are credited. 
Citation: Geramizadeh B, Marzban S, Karamifar N, Omidifar N, Shokripour M, et al. (2012) Diagnosis of Subcutaneous Metastatic Deposits by Fine Needle Aspiration. J Cytol Histol 3:151. doi:10.4172/2157-7099.1000151

Page 2 of 4

\begin{tabular}{|c|c|c|c|c|}
\hline Site of primary cancer & Number of cases & Site of subcutaneous metastasis & Sex & Type \\
\hline Breast & 6 & Chest wall (4) & $F(4)$ & Infiltrating ductal carcinoma \\
\hline Esophagus & 2 & Chest wall (2) & $M(2)$ & SCC \\
\hline Larynx & 2 & Neck (2) & $M(2)$ & SCC \\
\hline Lung & 1 & flank & M & SCC \\
\hline Bladder & 2 & Abdominal wall & $M(2)$ & TCC \\
\hline Liver & 2 & Abdominal wall & $M(2)$ & $\mathrm{HCC}$ \\
\hline Colon & 1 & Thigh & $\mathrm{F}$ & Adenocarcinoma \\
\hline Adrenal & 1 & Elbow & M & Adrenocortical carcinoma \\
\hline Kidney & 1 & Scalp & $\mathrm{F}$ & $\mathrm{RCC}$ \\
\hline Testis & 1 & Chin & M & Choriocarcinoma \\
\hline Soft Tissue & 3 & $\begin{array}{l}\text { Thigh (2 MFH) } \\
\text { Leg (Ewing) }\end{array}$ & $\begin{array}{l}\mathrm{M}(2 \mathrm{MFH}) \\
\mathrm{F} \text { (Ewing's) }\end{array}$ & $\begin{array}{l}\text { MFH } \\
\text { Ewing's sarcoma }\end{array}$ \\
\hline Bone & 1 & Neck & $F$ & Chondrosarcoma \\
\hline Stomach & 1 & Chest wall & $\mathrm{F}$ & NonHodgin's lymphoma \\
\hline Bone Marrow & 1 & Elbow & M & Multiple Myeloma \\
\hline
\end{tabular}

Table 1: Shows the characteristic findings in 25 patients with subcutaneous nodules.

There was also a patient, known case of renal cell carcinoma who presented with a scalp subcutaneous nodule. (Figure 6)

We had a patient with multiple myeloma and elbow metastasis. Diffuse large B cell lymphoma also presented with metastasis to the chest wall subcutaneous tissue.

Three of the patients with subcutaneous metastasis in this series were known cases of soft tissue sarcoma (2 malignant fibrous histiocytoma and one Ewing's sarcoma) who presented with forearm, thigh and leg metastasis respectively.

Overall the most common site of metastasis has been chest wall, followed by neck.

The size of the lesions varied from 0.5 to $4 \mathrm{~cm}$. All of our patients presented with a single well or ill-defined subcutaneous nodule

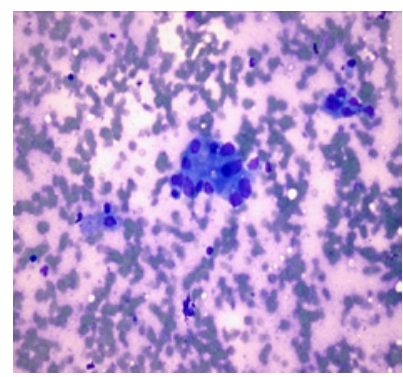

Figure 1a: Aspirate from chest wall subcutaneous nodule shows infiltrating ductal carcinoma of breast. (Wright stain X250).

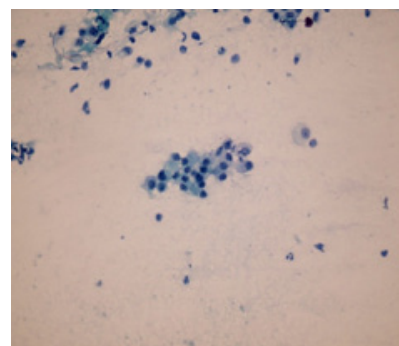

Figure 1b: Another aspirate from metastatic subcutaneous nodule of the breast shows loose clusters of malignant ductal epithelial cells. (Pap stain X 100)

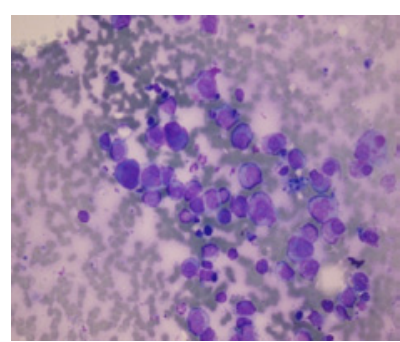

Figure 2: Smears of abdominal subcutaneous mass in a patient with bladder TCC show isolated highly atypical large cells with plenty of cytoplasm and prominent nucleoli. (Wright stain X 250).

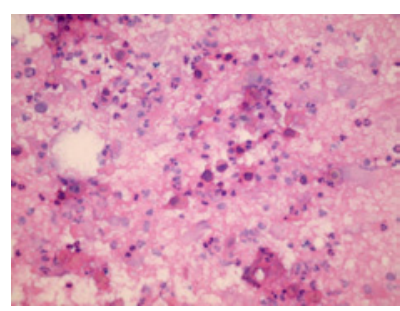

Figure 3: Smears from subcutaneous nodule in a patient with previous lung SCC show isolated highly atypical keratinized cells with hyperchromatic nuclei in necrotic dirty background. (Pap stain X100).

(Figures $7 \mathrm{a}$ and $7 \mathrm{~b}$ ). There was no ulcerated nodule. All of the cases were confirmed by histology and tissue biopsy.

The cytomorphology of metastatic lesions were compatible with the morphology of the primary in all cases.

Overall no false positive and no false negative diagnosis was made during this study.

\section{Discussion}

Subcutaneous metastasis of cancers can be secondary to direct extension from tumor or by lymphatic or vascular route [2]. This metastasis can occur everywhere in the subcutaneous tissue but they tend to be close to the primary cancer [4]. Subcutaneous tissue of chest is mostly involved by breast and lung cancers but abdominal malignancies tend to involve abdominal wall subcutaneous tissue [2].

In this study we had 6 cases of breast cancer with chest wall 
Citation: Geramizadeh B, Marzban S, Karamifar N, Omidifar N, Shokripour M, et al. (2012) Diagnosis of Subcutaneous Metastatic Deposits by Fine Needle Aspiration. J Cytol Histol 3:151. doi:10.4172/2157-7099.1000151

subcutaneous metastasis. The most likely site for skin and subcutaneous metastases, from breast carcinoma, in women has been the chest wall.

After chest wall, the most frequent site of subcutaneous metastasis has been neck [5]. We've had 2 cases of laryngeal Squamous Cell Carcinomas (SCC) with subcutaneous metastasis in the neck regions which has been confirmed by tissue biopsy. Laryngeal SCC most commonly metastasizes to lung and liver [6]. Subcutaneous metastasis in this tumor has been rarely reported. Most common site of this metastasis has been in the neck which can be accurately diagnosed by FNAC with the presence of clusters of highly atypical cells in necrotic background $[7,8]$.

In this study we had another case of metastatic SCC from lung to the subcutaneous region of the flank which showed clusters of highly atypical cells in necrotic background. Subcutaneous area is an uncommon site of metastasis in lung cancer, most of which have been located in the chest wall [9].

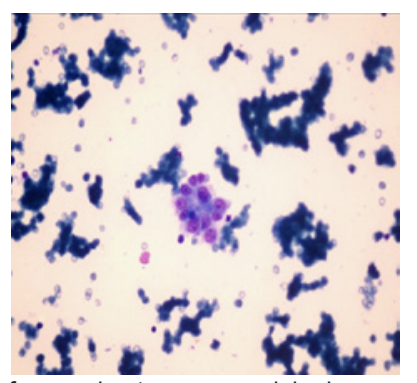

Figure 4: Smears from subcutaneous nodule in a patient with previous diagnosis of RCC show bland looking epithelial cells with plenty of cytoplasm. (Wright stain $X 250$ )

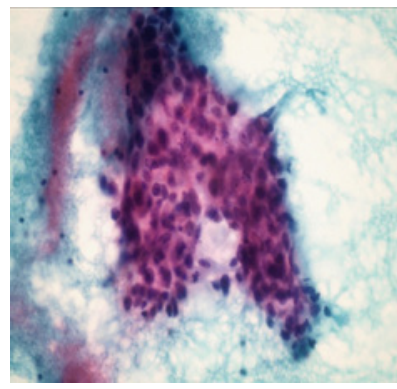

Figure 5: Smears from subcutaneous metastasis from adrenocortical carcinoma show clusters of atypical cells with prominent nucleoli. (Pap X 250).

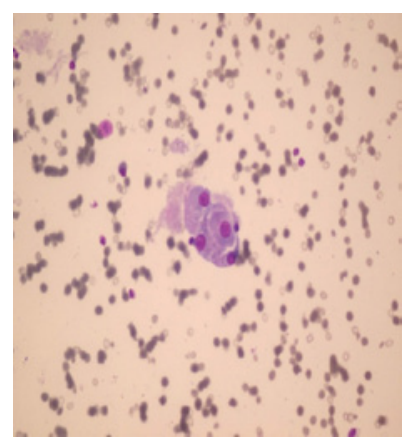

Figure 6: Smears of scalp nodule metastasis from RCC show small groups of bland looking cells with plenty of granular cytoplasm. (Wright stainX250).

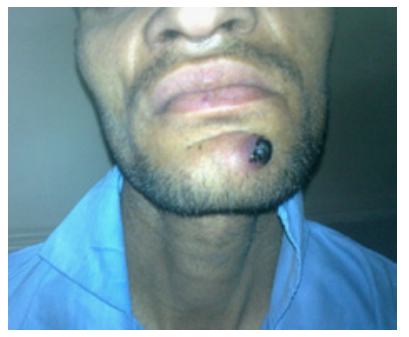

Figure 7a: A flank subcutaneous mass in a patient with lung SCC.

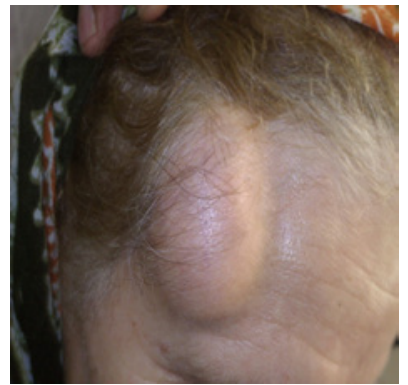

Figure 7b: Large subcutaneous mass in a patient with RCC.

We had another 2 cases of esophageal SCC with subcutaneous metastasis in the chest wall. Fine needle aspiration of both cases were very similar and just the same as two laryngeal and one lung SCCs with subcutaneous metastasis. Most of the reported cases of esophageal cancer and subcutaneous metastasis have been from esophageal adenocarcinoma and esophageal SCC with subcutaneous metastasis is extremely rare [10]. To the best our knowledge, diagnosis of metastatic subcutaneous SCC from esophagus with FNAC has not been reported.

Subcutaneous metastasis of Transitional Cell Carcinoma (TCC) has rarely been reported and most of them show metastasis to lymph node, liver and lung [11]. FNA cytology can be very helpful for this diagnosis to exclude other differential diagnoses such as abscess and inflammatory process $[12,13]$. In this study we had two patients which were known cases of bladder TCC presented with abdominal and cervical subcutaneous mass. FNAC smears of both cases were very similar and helpful.

Adenocarcinoma of colon can also rarely show metastasis to subcutaneous tissue in the final stages of the disease [14]. Role of the FNAC is very rarely emphasized in the literature $[1,4]$. We had a case of colon adenocarcinoma with subcutaneous metastasis to the thigh which has been previously reported as a letter to the editor [15].

Another very rare case of subcutaneous metastasis was a patient with the previous diagnosis of adrenocortical carcinoma, presented with an axillary superficial subcutaneous mass. FNAC showed isolated and clusters of highly atypical malignant cells, which was reported as positive for malignancy. However tissue biopsy and immunohistochemistry confirmed metastasis from adrenocortical tumor. To the best of our knowledge metastatic adrenocortical carcinoma with subcutaneous metastasis has not been previously reported.

Among these 25 patients, there was a patient with renal cell carcinoma metastatic to the subcutaneous tissue of scalp. Metastatic RCC to the head and neck has been reported in quite a few case reports [16]. 
Citation: Geramizadeh B, Marzban S, Karamifar N, Omidifar N, Shokripour M, et al. (2012) Diagnosis of Subcutaneous Metastatic Deposits by Fine Needle Aspiration. J Cytol Histol 3:151. doi:10.4172/2157-7099.1000151

In our 25 patients there was a patient with multiple myeloma, presented with cutaneous extramedullary plasmacytoma in the axillary area. This event has been rarely reported [17]. According to our experience, FNAC is a very accurate and rapid method for this diagnosis, but to the best of our knowledge this method has not been previously reported in multiple myeloma.

Another patient in this series was a case of gastric diffuse large B cell lymphoma with a subcutaneous mass on her chest wall. Subcutaneous metastasis of hematologic malignancies such as lymphoma diagnosed by FNAC has been reported in the previous reports [4]. Our patient was on chemotherapy when noticed a subcutaneous nodule in her chest. FNAC showed many isolated highly atypical cells diagnostic for lymphoma cells.

In this series, two cases have been diagnosed as malignant fibrous histiocytoma of right thigh and left arm, both presented with subcutaneous masses in left thigh. FNAC showed highly atypical mono, and multinucleated cells with hyperchromatic nuclei, marked pleomorphism and intense anisonucleosis admixed with some chronic inflammatory cells. It was diagnosed as pleomorphic sarcoma, tissue biopsy confirmed the diagnosis. Subcutaneous metastasis of sarcoma is usually a late event and heralds a poor prognosis [18].

Another patient with known malignancy has been diagnosed as chondrosarcoma of humerous who presented with cervical subcutaneous mass. FNAC showed myxoid background with a few atypical cells. Distant subcutaneous metastasis of chondrosarcoma has very rarely been reported [19], but role of FNAC has not been emphasized.

Our last case was a patient with Ewing's sarcoma of ankle, who was successfully resected and after less than a year presented with a subcutaneous nodule in her leg. Subcutaneous and cutaneous extraskeletal Ewing's sarcomas have been reported but skeletal Ewing's sarcoma with recurrence presented as a subcutaneous mass has not been reported to be diagnosed by FNAC [20].

\section{Conclusion}

All of our cases were accurately diagnosed by FNAC, so we want to emphasize on the accuracy of FNAC in the patients with a known malignancy, who present with a subcutaneous nodule. It is an accurate, noninvasive, fast and cost effective method for the diagnosis of the patients suspected to subcutaneous metastasis in all types of malignancies i.e. sarcoma, carcinoma and hematologic malignancies.

\section{References}

1. Sharma S, Kotru M, Yadav A, Chugh M, Chawla A, et al. (2009) Role of fineneedle aspiration cytology in evaluation of cutaneous metastases. Diagn Cytopathol 37: 876-880.

2. Bansal R, Patel T, Sarin J, Parikh B, Ohri A, et al. (2011) Cutaneous and subcutaneous metastases from internal malignancies: an analysis of cases diagnosed by fine needle aspiration. Diagn Cytopathol 39: 882-887.

3. Bhanot UK, Rauniyar SK, Mital VP (2007) Fine needle aspiration cytology of metastatic skin nodules. A report of 2 cases. Acta Cytol 51: 95-98.

4. David O, Kluskens L, Reddy V, Gattuso P (1998) Malignant cutaneous and subcutaneous abdominal wall lesions: a fine-needle aspiration study. Diagn Cytopathol 19: 267-269.

5. Gupta RK, Naran S (1999) Fine needle aspiration cytology of cutaneous and subcutaneous metastatic deposits from epithelial malignancies. An analysis of 146 cases. Acta Cytol 43: 126-130.

6. Kumar N, Bera A, Kumar R, Ghoshal S, Angurana SL, et al. (2011) Squamous cell carcinoma of supraglottic larynx with metastasis to all five distal phalanges of left hand. Indian J Dermatol 56: 578-580.

7. Horiuchi N, Tagami H (1992) Skin metastasis in laryngeal carcinoma. Clin Exp Dermatol 17: 282-283.

8. GrossI N, Tadros TS, Naib ZM (1996) Sarcomatoid carcinoma of the larynx with neck and distant subcutaneous metastases. A case report with fine needle aspiration cytology. Acta Cytol 40: 756-760.

9. Sim JH, Kim JE, Lee SH, Cho MK, Lee JS, et al. (2011) Vulvar skin metastasis of lung squamous cell carcinoma. Ann Dermatol 23: S179-181.

10. Balukrishna S, Jennifer P, Viswanathan PN (2011) Solitary Subcutaneous Metastasis from Squamous Cell Carcinoma of the Esophagus: A Case Report and Brief Review of Literature. J Gastrointest Cancer 42: 269-271.

11. Atmaca AF, Akbulut Z, Demirci A, Belenli O, Alici S, et al. (2007) Multiple subcutaneous Nodular Metastases from Transitional Cell Carcinoma of the Bladder. Pathol Oncol Res 13: 70-72.

12. Kumar PV, Salimi B, Musallaye A, Tadayyon A (2000) Subcutaneous metastasis from transitional cell carcinoma of the bladder diagnosed by fine needle aspiration biopsy. A case report. Acta Cytol 44: 657-660.

13. Geramizadeh B, Tavakol MH (2007) Fine needle aspiration of a subcutaneous mass caused by metastatic transitional cell carcinoma. Acta Cytol 51: 487-488.

14. Llaguna OH, Desai P, Fender AB, Zedek DC, Meyers MO, et al. (2010) Subcutaneous Metastatic Adenocarcinoma: An Unusual Presentation of Colon Cancer - Case Report and Literature Review. Case Rep Oncol 3: 386-390.

15. Geramizadeh B, Maghboul M (2010) Subcutaneous metastasis from colon adenocarcinoma diagnosed by fine needle aspiration cytology. Acta Cytol 54 1057-1058.

16. Langille G, Taylor SM, Bullock MJ (2008) Metastatic renal cell carcinoma to the head and neck: summary of 21 cases. J Otolaryngol Head Neck Surg 37: 515-521.

17. Gaba RC, Kenny JP, Gundavaram P, Katz JR, Escuadro LR, et al. (2011) Subcutaneous plasmacytoma metastasis precipitated by tunneled central venous catheter insertion. Case Rep Oncol 4: 315-322.

18. Wang WL, Bones-Valentin RA, Prieto VG, Pollock RE, Lev DC, et al. (2012) Sarcoma metastases to the skin: a clinicopathologic study of 65 patients. Cancer 118: 2900-2904.

19. Damron TA, Rock MG, Unni KK (1995) Subcutaneous involvement after a metacarpal chondrosarcoma. Case report and review of literature. Clin Orthop Relat Res: 189-194.

20. Banerjee SS, Agbamu DA, Eyden BP, Harris M (1997) Clinicopathologica characteristics of peripheral primitive neuroectodermal tumour of skin and subcutaneous tissue. Histopathology 31: 355-366. 